\begin{tabular}{|l|l|}
\hline $\begin{array}{l}\text { Postprint } \\
\text { Version }\end{array}$ & 1.0 \\
\hline Journal website & $\underline{\text { http://dx.doi.org/10.1016/j.ijnurstu.2009.11.016 }}$ \\
\hline Pubmed link & $\underline{\text { http://www.ncbi.nlm.nih.gov/pubmed/20022007 }}$ \\
\hline DOI & $10.1016 / j . i j n u r s t u .2009 .11 .016$ \\
\hline
\end{tabular}

This is a NIVEL certified Post Print, more info at http://www.nivel.eu

\title{
Attitudes of nursing staff towards electronic patient records: A questionnaire survey
}

\author{
ANKE J.E. DE VEER ${ }^{\mathrm{A},}$ AND ANNEKE L. FRANCKE ${ }^{\mathrm{A}, \mathrm{B}}$ \\ a The Netherlands Institute for Health Services Research (NIVEL), P.O. Box 1568, 3500 BN Utrecht, The \\ Netherlands \\ ${ }^{b}$ Department of Public and Occupational Health, EMGO Institute for Health and Care Research (EMGO+) \\ of the VU University Medical Center Amsterdam, The Netherlands
}

\begin{abstract}
Background: A growing number of health care organizations are implementing a system of electronic patient records (EPR). This implies a change in work routines for nursing staff, but it could also be regarded as an opportunity to improve the quality of care.

Objective: The objective of this paper is to obtain more insight into the usefulness of EPR as perceived by nursing staff and to clarify the determinants of nursing staff's acceptance of EPR. Determinants were tested using an extended version of the Technology Acceptance Model.

Design: Nursing staff members (NAs and RNs) completed a survey questionnaire about the use of EPR in health care, and their experiences, perceptions and attitudes regarding EPR.

Settings: All nursing staff members were working in Dutch hospitals, psychiatric organizations, care organizations for mentally retarded people, home care organizations, nursing homes or homes for the elderly.

Participants: The study population is a nationally representative Dutch research sample, further referred to as the Nursing Staff Panel. The Panel consists of a permanent group of Nursing Assistants (NAs) and Registered Nurses (RNs), who are prepared to fill in a postal questionnaire twice a year on average. In January 2009, 685 participants completed the questionnaire.

Results: Nursing staff members associate EPR with improved care, especially qualitatively better and safer care. They also expect an increase in costs of care, while anticipating only a relatively small rise in the number of patients that can be cared for. In general, the effects of EPR on the work circumstances of nursing staff are expected to be negative. Job-related characteristics were found to be determinants of attitudes towards using EPR. A relatively positive attitude towards EPR was found in three categories of nursing staff in particular, i.e. staff working at least $30 \mathrm{~h}$ per week, staff already using EPR and staff working in hospitals. Nursing staff in management positions also tend to have a more positive attitude. When the Technology Acceptance Model was tested, attitudes towards EPR were primarily associated with job-related characteristics and perceived usefulness with respect to quality of care.

Conclusions: The implementation strategies for EPR need to take account of the job characteristics of the intended future users. If implementation is to be successful, it is important that the users understand the beneficial effects of EPR on the quality of care.
\end{abstract}


Veer, A.J.E. de, Francke, A.L. Attitudes of nursing staff towards electronic patient records: a questionnairef
survey. International Journal of Nursing Studies: $2010,47(7), 846-854$

\section{What is already known about the topic?}

- A growing percentage of nursing staff works with electronic patient records (EPR).

- In general, the acceptance of new technologies has been proven to depend on the perceived usefulness of the new technology.

\section{What this paper adds}

- Nursing staff perceive EPR primarily as a means to improve the quality of care and not as a tool to increase cost effectiveness or to make their jobs more attractive. Moreover, EPR is associated with higher costs, increased workload and more administrative tasks.

- Job characteristics and the perceived effects of EPR on the quality of care determine about one-third of the attitude of nursing staff towards using EPR.

- Perceived usefulness of EPR with respect to cost effectiveness and job attractiveness are only weak determinants of attitudes towards using EPR.

\section{INTRODUCTION}

More and more health care organizations are introducing electronic systems to store patient information. These are known as electronic patient records (EPR), although the systems can be labelled differently locally, using terms such as electronic nursing records, electronic health records, or computer-based patient record systems. The functionalities of these systems may differ, e.g. some are used by nursing staff only, whereas others are also used by physicians and other professionals. This paper is concerned with the experiences and attitudes of nursing staff where the use of EPR is concerned and it validates the Technology Acceptance Model that predicts attitudes towards using EPR.

Characteristics of the professionals themselves play an important role in whether new work routines are implemented and actually used ([Fleuren et al., 2004] and [Francke et al., 2008]). Implementing EPR implies a new way of structuring work. The nurse must have access to a computer to read or fill in a patient record for instance, and information registered will be more standardized as a consequence. In addition, nursing staff members must be able and willing to work with computers. Several studies have described nurses' negative attitudes towards growing computerization ([Dahm and Wadensten, 2008], [Smith et al., 2005] and [Timmons, 2003]). Nurses often consider technology not to fit in with the personal nature of care giving and fail to see the advantages for nursing practice ([Bond, 2007], [Goris and Mutsaers, 2008] and [Nilsson et al., 2008]). New technology like EPR must provide clear advantages for nursing staff, e.g. improving the quality of care or reducing the workload, since its usage seems unlikely to become part of daily routine otherwise.

The well-known Technology Acceptance Model ([Davis, 1989] and [Venkatesh and Davis, 2000]) provides a framework for predicting the use of EPR from the viewpoint of the professional. In the original version of the Technology Acceptance Model (TAM), the usage of a technological innovation is predicted by two concepts: "perceived ease of use" and "perceived usefulness". Perceived ease of use refers to the degree to which a person believes that using the technology will be free of effort, while perceived usefulness is defined as the degree to which a person believes that using a particular technology will enhance his or her job performance. According to Davis, perceived usefulness plays a more important role than ease of use, because users are often willing to cope with difficulty of use in technology that provides critically needed functionality. No amount of ease of use, however, can compensate for a technology that does not perform a useful function. Perceived usefulness has consistently been found to be a strong determinant of usage intentions, whereas perceived ease of use has exhibited a less consistent effect across studies (Venkatesh and Davis, 2000). In TAM2 determinants of perceived usefulness were added to the original TAM (Venkatesh and Davis, 2000) in order to improve the design of organizational interventions that would increase user acceptance and usage of new technology. TAM or TAM2 have been validated in at least 24 empirical studies and have been proven to be reliable and robust models (Yarbrough and Smith, 2007).

The present research describes determinants of nursing staff attitudes towards using EPR by using a research model based on an extension of the original TAM (Fig. 1). Attitude towards using EPR refers to positive or negative feelings about introducing EPR. In Fig. 1 the attitudes of nursing staff towards using EPR are formed by its perceived usefulness. Three domains of perceived usefulness are distinguished: (1) the expected effects of EPR usage on the quality of the care; (2) the expected effects of EPR usage on the 
Veer, A.J.E. de, Francke, A.L. Attitudes of nursing staff towards electronic patient records: a questionnairesurvey. International Journal of Nursing Studies: 2010, 47(7), 846-854

cost effectiveness of care; and (3) the expected effects of EPR usage on the work circumstances of nursing staff. In our model, perceived usefulness and attitude are influenced by three groups of determinants. Firstly, user characteristics are expected to play a role (Chen et al., 2008). For example, younger and more highly educated professionals are expected to perceive more positive effects and will therefore be more inclined to use EPR. Secondly, the organizational environment is expected to play a role. Nursing staff who closely co-operate with physicians (e.g. in hospitals and psychiatry) for example, may experience more usefulness if EPR facilitates the information exchange with physicians. In addition, nursing staff who are already used to working in a more technological environment like hospitals can be expected to accept EPR more easily, while nursing staff members providing home care to people living independently will probably experience more practical barriers, because they will not have access to computer records when they visit patients at home. Thirdly, previous experiences with EPR are expected to play a role. Venkatesh and Davis (2000) state that users' knowledge of and beliefs about a technological innovation are vague before the innovation is introduced. After EPR has been implemented they know more about its strengths and weaknesses and this influences perceived usefulness and attitudes.

\section{[FIGURE 1]}

\subsection{Aim of the paper}

The aim of this paper is to explore the determinants of attitudes of nursing staff towards using EPR and to test a model largely based on TAM. Understanding these determinants and the opinions of nursing staff on EPR is important for the further implementation of EPR in nursing practice.

Research questions and hypotheses:

(1) What is the perceived usefulness of EPR with regard to the quality of care, cost effectiveness and work circumstances of nursing staff?

(2) Perceived usefulness has a significant effect on attitudes towards using EPR (Hypothesis 1).

(3) User characteristics, previous experiences with EPR and the specific health care sector have a significant effect on attitudes towards using EPR (Hypothesis 2).

(4) The effects of user characteristics, previous experience with EPR and health care sector respectively on attitudes towards using EPR are mediated by perceived usefulness (Hypothesis 3).

\section{METHODS}

\subsection{Participants}

The study population is a nationally representative Dutch research sample, further referred to as the Nursing Staff Panel. The Panel consists of a permanent group of Nursing Assistants (NAs) and Registered Nurses (RNs) who are prepared to fill in a postal questionnaire twice a year on average. Dutch NAs have received 3 years of professional training (so Dutch NAs receive much more professional training than CNAs in the USA for example). Dutch RNs are educated at two different levels and comprise nurses at associate (foundation [UK]) degree level (3-3.5 years of professional training) and nurses at a bachelor's degree level (at least 4 years of professional training). Only nurses with a bachelor's degree can study for a master's degree at university.

Candidates for the Nursing Staff Panel were recruited from a random sample of nursing staff registered with the National Employee Insurance Agency, where all Dutch employees are required to be insured. This Agency which has the addresses of all employees in Dutch health care as well as their job titles asked a random sample of nursing staff whether they were willing to participate in the Panel. The Panel coordinator (AdV) selected 1018 persons to form the Nursing Staff Panel, making the selection in such a way that members represent the nursing staff in the largest health care sectors in the Netherlands, i.e. hospitals, psychiatry, care for mentally disabled people, home care, nursing homes and homes for the elderly. The age and gender of the selected group correspond to the age and gender of the population of Dutch nursing staff. This representative group makes up the Nursing Staff Panel. The questionnaire was sent to 1018 members of the Panel in January 2009, followed by two reminders about 14 days and 28 days later.

A total of 685 nursing staff members completed a postal questionnaire about the use of technology (response rate 67\%). Most respondents (89\%) delivered direct patient care exclusively, while $11 \%$ were also involved in management tasks. The respondents were employed to work $24 \mathrm{~h}$ a week on average (standard deviation $8 \mathrm{~h}$ ) and had been working in care for an average of 21 years (standard deviation 9 
Veer, A.J.E. de, Francke, A.L. Attitudes of nursing staff towards electronic patient records: a questionnairesurvey. International Journal of Nursing Studies: 2010, 47(7), 846-854

years). Most respondents were female (90\%). We compared the respondents and non-respondents and found no statistically significant differences in the percentages of females in both groups $(p>.05)$, although we did find a statistically significant difference in age, the non-respondents group being younger (average 43 years) than the respondents group (average age 45 years, standard deviation 9 years). This contributes to the finding that the average age of the respondents group is higher than the population of nursing staff registered with Employee Insurance Agency, although the Panel is largely representative of all Dutch NAs and RNs working in the Netherlands.

\subsection{Questionnaire}

The questionnaire used addressed perceptions of new technologies, such as sensors, electronic monitoring of medical data, telecare and EPR but, for the purposes of this paper, we focused only on the questions concerning EPR. The relevant questions started with a general description of EPR and had pre-structured, forced-choice answers. EPR was described as "electronic storage of information about patients. Other professionals in your health care organization who provide care to the patient can view the information from their own workplace and are able to add information."

Specific questions covered the following:

- Previous experiences with EPR. The respondents chose one of the following answers: 'I have used EPR myself', 'I have not used EPR myself, but colleagues in my organization have', 'There is no experience with EPR in my organization.' More than half of the respondents $(n=394,54.6 \%)$ had not used EPR before, whereas the remainder had $(\mathrm{n}=307,44.8 \%)$. Four respondents did not answer this question $(0.6 \%)$.

- Perceived usefulness of EPR. Davis (1989) and Venkatesh and Davis (2000) developed a scale measuring perceived usefulness. The items refer to global job aspects that are expected to be applicable in a broad range of settings, but our research focused on nurses within health care and we were able to choose more specific items as a consequence. We took the three clusters that Davis (1989) originally distinguished as being elements of perceived usefulness, i.e. job effectiveness, productivity and time savings, and the importance of the technology to one's job and then took the further step of formulating items within each cluster, choosing items that nursing staff have indicated as important elements (De Veer et al., 2007) and that fitted into one of the three clusters. Ten kinds of possible effects of EPR were pre-described (see Table 1) and respondents were asked to indicate on a 5-point scale whether he or she perceived EPR as having a strong positive effect (2), a positive effect $(1)$, no effect $(0)$, a negative effect $(-1)$ or a strong negative effect $(-2)$ on each listed item. The possible effects related to:

(a) quality of care (4 items, reliability Cronbach's alpha $=.82)$. Items concerned quality of care, quality of life, stimulating patient independence and safety;

(b) cost effectiveness of care ( 2 items). One item concerned the costs of care and the other the number of patients that can be given care, but as the responses to these two items did not form a reliable scale (Pearson's $r=.23$ ) they are considered separately in the analyses;

(c) the effects of EPR on the work circumstances of nursing staff (4 items, reliability Cronbach's alpha $=.63)$. Items concerned physical workload, general workload, job attractiveness, and number of administrative tasks.

\section{[TABLE 1. ]}

General attitude towards using EPR was operationalized as the perceived necessity of introducing EPR into home care ('absolutely necessary' (score $=3$ ); 'preferable, but not necessary' (score $=2$ ), 'not necessary and not preferable' (score $=1)$ ). The option of filling in 'I don't know' was also offered and this answer was given by 70 respondents $(10.2 \%)$. Five persons $(0.7 \%)$ did not answer this question. The hypothesized model was only tested using the data of the respondents with scores 1,2 or $3(n=610)$.

The face validity and content validity of the draft questionnaire were assessed individually by five experts in the field of nursing care; two researchers in this field, two individuals with considerable practical knowledge of working as a nurse, and one representative of the Ministry of Health. They were asked to comment individually on the face validity and content validity of the questionnaire and to judge whether the questions and possible answers were unequivocal, which resulted in minor modifications to the questionnaire. 
Veer, A.J.E. de, Francke, A.L. Attitudes of nursing staff towards electronic patient records: a questionnairef survey. International Journal of Nursing Studies: 2010, 47(7), 846-854

\subsection{Statistical analyses}

The perceived usefulness of EPR (research question 1) is reflected in the percentages of nursing staff that perceive a negative effect, no effect or a positive effect on the said ten items individually. The 5-point scale originally used was recoded into a 3-point scale, on which a negative effect corresponded with scores -1 or -2 , no effect with 0 , and a positive effect with 1 or 2 . The mean effect was calculated using the full range of possible scores $(-2,-1,0,1,2)$. We used $95 \%$ confidence intervals for the average effect, to determine whether nursing staff expected a statistically significant effect of EPR usage on the quality of care, the cost effectiveness of the care, and work circumstances of nursing staff respectively.

When testing the model shown in Fig. 1, we first used ANOVA to explore bivariate relationships between independent variables (including hypothesized mediating variables) and the dependent variable 'attitude towards using EPR'.

In the second step, the relationship between external variables and attitude was explored using a stepwise multiple regression analysis with external variables as independent variables and attitude as dependent variable. This was done using the cases on either variable used in the regression analyses $(n=574)$. If there is no relationship, there is no need for further exploration of a possible mediating role of experienced usefulness.

After this regression analysis, in a third step we added perceived usefulness in four separate analyses for each aspect of usefulness. The hypothesized indirect relationships of external variables and attitude are confirmed by the analyses if the relationship (found in step 2) significantly weakens or disappears after adding perceived usefulness.

The analyses were performed using Stata 10.1. The criterion for statistical significance is .05.

\section{RESULTS}

\subsection{Perceived usefulness of EPR}

We defined perceived usefulness as the degree to which a person believes that using a particular technology will enhance his or her job performance. Table 1 shows the perceived usefulness of EPR with regard to the quality of care, the cost effectiveness of the care, and work circumstances. The majority of the nursing staff perceived no effects of EPR on the patients' quality of life (63.2\%) and independence $(75.8 \%)$, but the majority perceived positive effects $(60.3 \%$ and $55.8 \%)$, however, with regard to the general quality and safety of the care.

The respondents differed in their perceptions of the costs of care, but overall they expected costs to rise (average effect -.25). Most nursing staff (64.7\%) did not perceive EPR as having an effect on the number of patients that can be cared for.

Where work circumstances were concerned, the majority perceived no effects on the physical job load $(77.6 \%)$. Nursing staff members did, however, perceive a negative effect on general workload and the amount of administrative tasks (averages -.33 and -.46). The perceived effects of EPR on job attractiveness varied, but were slightly positive on average (average effect .09).

One-fifth of the nursing staff (20.3\%) did not want EPR to be introduced into their organization; $45.1 \%$ found it desirable and $34.6 \%$ absolutely necessary to use EPR.

Hypothesis 1 Perceived usefulness has a significant effect on attitudes towards EPR

The data confirm the first hypothesis. All four aspects of perceived usefulness had statistically significant individual relationships to attitudes towards using EPR (Table 2). Nursing staff members who believed that EPR improves the quality of care, reduces the costs of care, increases the number of patients that can be cared for, or improves work circumstances showed a more positive attitude towards using EPR.

Hypothesis 2 User characteristics, previous experience with EPR, and health care sector have a significant effect on attitudes towards using EPR

\section{[TABLE 2.]}

The hypothesis that user characteristics co-determine attitudes to using EPR was largely confirmed. Nursing staff members with a high educational level, in management positions, and working at least $30 \mathrm{~h}$ per week had a more positive attitude towards using EPR (Table 3), although the number of years of working in nursing practice was not related to attitude. 
[TABLE 3.]

As we also hypothesized, previous experience with EPR was strongly related to attitudes towards using EPR, with nursing staff who already work with EPR showing a more positive attitude.

Also as expected, health care sector influenced attitude; nursing staff in hospitals were most positive, whereas nursing staff in home health care were least positive.

Hypothesis 3 The influence of user characteristics, previous experience with EPR and health care sector on attitude to using EPR are mediated by the perceived usefulness

We tested the multiple relationships between the external variables and attitude. Table 4 shows that the external variables together explain $18 \%$ of the variance within attitudes. Attitude was mainly associated with hours employed per week, previous experience with EPR, and health care sector. Job position showed a weak relationship $(\mathrm{p}<.10)$ with attitude towards using EPR.

\section{[TABLE 4. ]}

The betas do not change much when perceived usefulness is added (Table 5), apart from the fact that relationships that are statistically significant in Table 4 sometimes lost statistical significance after perceived usefulness was included in the regression analysis. For example, after adding perceived usefulness regarding quality of care, there is no longer a correlation with job position. The same applies to the effect of working in nursing homes and homes for the elderly after adding the perceived usefulness item regarding the number of patients that can be cared for.

\section{[TABLE 5. ]}

Adding an aspect of perceived usefulness always showed a significant increase in explained variance, although only the increase of $14 \%$ after adding the perceived effect on quality of care is substantial.

We can conclude, therefore, that attitudes towards using EPR are mainly explained by health care sector, previous experience with EPR, number of hours employed per week and perceived usefulness in relation to the quality of care. No mediating effects were found for perceived usefulness and thus the third hypothesis was not confirmed.

\section{DISCUSSION AND CONCLUSION}

\subsection{Discussion of findings}

The results show that nursing staff associate EPR with an improvement in several aspects of care, especially qualitatively better and safer care. They also expect an increase in costs of care, but anticipate only a relatively small rise in the number of patients that can be cared for, which is remarkable, because a systematic review of the literature on the benefits and costs of EPR in hospitals showed clear economic benefits for EPR (Uslu and Stausberg, 2008).

The expected effects of EPR on the work circumstances of nursing staff are negative in general and EPR is mainly associated with an increase in administrative tasks and workload. This is in accordance with research results among physicians, which have suggested that information systems can require more time per physician than paper-based registration, in the beginning at least (Overhage et al., 2001). This was mainly due to a lack of experience with the new technology (which diminishes with time) and duplicative administrative tasks. No clear time savings were found, however, even with experienced users.

Job-related characteristics are found to be connected with attitudes towards using EPR. In particular, nursing staff working at least $30 \mathrm{~h}$ per week, those already working with EPR, and those working in hospitals have a relatively positive attitude, while nursing staff members in management positions also tend to have a more positive attitude.

Attitudes towards using EPR are primarily associated with perceived usefulness with regard to the quality of care. The influence of perceived cost effectiveness and of work circumstances is marginal, which is remarkable, since Lee et al. (1996) found that efficiency was more strongly associated with user satisfaction with Physician Order Entry, than with characteristics related to the quality of patient care.

In our study we found a relationship with the number of employment hours per week, previous experience, and health care sector. We found no consistent relationship with job position and educational level. In other studies too, the empirical evidence of the role of external variables as determinants of nurses' attitude 
Veer, A.J.E. de, Francke, A.L. Attitudes of nursing staff towards electronic patient records: a questionnairesurvey. International Journal of Nursing Studies: 2010, 47(7), 846-854

towards technology is not unequivocal, with some finding statistically significant correlations while others did not (e.g. [Chen et al., 2008], [Dillon et al., 2005] and [Yu et al., 2008]).

\subsection{Methodological considerations}

The model tested explained $32 \%$ of the variance in attitude, which means that the majority of the variance remained unexplained. Venkatesh and Davis (2000) state that the opinions of colleagues and perceived ease of use also influence perceived usefulness and attitude towards using EPR and that these influences change with experience of EPR usage. We, however, only distinguished between nursing staff members who had already worked with EPR and those who had not and we have no information about how long respondents had already been working with EPR.

Another limitation of the study is that we only looked at nursing staff attitudes towards using EPR and attitude is not the same as actual usage. If someone has a positive attitude towards using EPR, this does not automatically imply that this person will actually use EPR. In addition, the original TAM is limited to predicting and explaining usage intentions and behaviour (also referred to as user acceptance) and does not necessarily extend to actual use.

Finally, the original TAM (and TAM2 as well) is a causal model, whereas we used our modified model in a non-causal way. We assumed, for example, that previous experience with EPR influenced attitudes, but our cross-sectional study design made it impossible to actually test what was cause and what was effect. It may be possible that nursing staff with a positive attitude started working with EPR earlier than those with a negative attitude.

\subsection{Theoretical implications}

This study tested an extended version of TAM ([Davis, 1989] and [Venkatesh and Davis, 2000]) and used this to explain the attitude of nursing staff towards using EPR. The addition of external variables was shown to increase the predictive value of the model. Perceived usefulness was expected to mediate the relationship between external variables and attitude in our extension of TAM, but we did not find clear evidence for a mediating effect of this kind, although we did find direct effects. Adding external variables increased the explanatory power.

Many studies have validated the usefulness of TAM or TAM2 in predicting technology acceptance. In these studies perceived usefulness is considered to be a single concept, so what this study adds is a breakdown of the concept of perceived usefulness into three facets, which are quality of care, cost effectiveness, and job attractiveness. The perceived effect of EPR on the quality of care added $14 \%$ explained variance in attitude; the other aspects of usefulness only added $1-2 \%$ explained variance. These results show that TAM is more valid if different aspects of perceived usefulness are distinguished.

This is of special relevance, because research suggests that physicians and nurses are different types of users of these kinds of technology, valuing different aspects of a technology (Lee et al., 1996).

\subsection{Practical implications}

Our study shows that nursing staff have a less positive attitude towards adopting EPR before this technology is actually introduced, which may be due to anxiety about working with computers and resistance to changing work routines (Dahm and Wadensten, 2008).

The practical implications of the present study for nursing managers are threefold. First, attitudes towards using EPR are related to several job characteristics of the nursing staff. When designing a strategy for implementing EPR, special attention (e.g. extra training) should be paid to NAs, nursing staff employed for only a small number of hours per week, and those not in management positions. This is of special importance in home care, where the nursing staff show a less positive attitude towards using EPR. It is probable that practical reasons play a role in home care, because it is not so easy to use EPR when you are constantly travelling from one patient to another. In hospitals, where the environment is more hi-tech, nursing staff are probably more open to new technologies.

Secondly, it must be taken into account that EPR is mainly regarded by nursing staff as a technology that leads to better quality of care and this fosters a positive attitude towards using EPR. Studies showing that the use of EPR actually enhances the quality of care and reduces risks will help to convince nursing staff of the benefits of EPR. Nursing staff also perceive negative aspects, such as higher costs, greater workload and more administrative tasks. Although these perceptions have a relatively small influence on attitudes towards using EPR, attention should be paid to these aspects when there are plans to introduce EPR. After a systematic review of the literature on physician acceptance of information technology, Yarbrough and 
Veer, A.J.E. de, Francke, A.L. Attitudes of nursing staff towards electronic patient records: a questionnairef survey. International Journal of Nursing Studies: 2010, 47(7), 846-854

Smith (2007) concluded that the requirement of additional time is one of the major barriers to technology acceptance.

Thirdly, it is important to be aware of the fact that nursing staff who have already worked with EPR have a more positive attitude towards using this technology. They can be role models for those who have not yet experienced working with EPR by showing how EPR can be used and indicating what nursing staff need in order to integrate EPR into their work routines.

\subsection{Conclusion}

If implementing is to be successful it is important that nursing staff understand the possible beneficial effects of EPR on the quality and safety of patient care. Other possible aspects, such as time savings, reduction of costs and reduction of administrative tasks might be relevant to managers or policy makers to implement EPR, but will not motivate nurses to use it. The implementation strategy also needs to take different job characteristics of the intended future users into account.

Author's contributions: Anke de Veer and Anneke Francke were the principal investigators and were responsible for study concept and design, analysis, interpretation of data and preparation of the manuscript.

Conflict of interest: All authors disclose no financial conflict of interest.

Funding: This research was financed by the Dutch Ministry of Health, which had an advisory role in giving suggestions about the research questions and subjects that were part of the questionnaire. The Ministry has no interest in whatever directions the results are pointing to. The opinions expressed in this article are those of the authors.

Ethical approval: The authors declare that no ethical approval was required for this study.

\section{REFERENCES}

Bond, 2007 C.S. Bond, Nurses' requirements for information technology: a challenge for educators, International Journal of Nursing Studies 44 (2007), pp. 1075-1078 10.1016/j.ijnerstu.2007.01.009.

Chen et al., 2008 J. Chen, K.F. Yang, F.I. Tang, C.H. Huang and S. Yu, Applying the technology acceptance model to explore public health nurses' intentions toward web-based learning: a crosssectional questionnaire survey, International Journal of Nursing Studies 45 (2008), pp. 869-878.

Dahm and Wadensten, 2008 M.F. Dahm and B. Wadensten, Nurses' experiences of and opinions about using standardised care plans in electronic health records-a questionnaire study, Journal of Clinical Nursing 17 (2008), pp.

Davis, 1989 F.D. Davis, Perceived usefulness, perceived ease of use, and user acceptance of information technology, MIS Quarterly 13 (3) (1989), pp. 319-340.

Dillon et al., 2005 T.W. Dillon, R. Blankenship and T. Crews, Nursing attitudes and images of electronic patient record systems, Computers, Informatics, Nursing 23 (3) (2005), pp. 139-145.

De Veer et al., 2007 A.J.E. De Veer, E.P. Poortvliet, B. Vogel and A.L. Francke, De aantrekkelijkheid van het beroep. Een peiling onder het Panel Verpleegkundigen \& Verzorgenden, LEVV/NIVEL, Utrecht (2007).

Fleuren et al., 2004 M. Fleuren, K. Wiefferink and T. Paulussen, Determinants of innovations within health care organizations. Literature review and Delphi study, International Journal for Quality in Health Care 16 (2) (2004), pp. 107-123.

Francke et al., 2008 A.L. Francke, M.C. Smit, A.J.E. de Veer and P. Mistiaen, Factors influencing the implementation of clinical guidelines for health care professionals: a systematic meta-review, BMC Medical Informatics and Decision Making 8 (2008), p. 38 10.1186/1472-6947-8-38. )

Goris and Mutsaers, 2008 A. Goris and H. Mutsaers, Ruimte voor arbeidsbesparende technologie om in 2025 voldoende zorg te bieden [Scope for labour-saving technology to offer adequate care in 2005], STG/Health Management Forum, Leiden (2008).

Lee et al., 1996 F. Lee, J.M. Teich, C.D. Spurr and D.W. Bates, Implementation of physician order entry: user satisfaction and self-reported usage patterns, Journal of the American Medical Informatics Association 3 (1996), pp. 42-55.

Nilsson et al., 2008 C. Nilsson, L. Skär and S. Söderberg, Swedish district nurses' attitudes to implement information and communication technology in home nursing, The Open Nursing Journal 2 (2008), pp. 6872. 
Veer, A.J.E. de, Francke, A.L. Attitudes of nursing staff towards electronic patient records: a questionnairef survey. International Journal of Nursing Studies: 2010, 47(7), 846-854

Overhage et al., 2001 J.M. Overhage, S. Perkins, W.M. Tierney and C.J. McDonald, Controlled trial of direct physician order entry: effects on physicians' time utilization in ambulatory primary care internal medicine practices, Journal of the American Medical Informatics Association 8 (2001), pp. 361-371. )

Smith et al., 2005 K. Smith, V. Smith, M. Krugman and K. Oman, Evaluating the impact of computerized clinical documentation, Computers, Informatics, Nursing 23 (3) (2005), pp. 132-138.

Timmons, 2003 S. Timmons, Nurses resisting information technology, Nursing Inquiry 10 (4) (2003), pp. 257-269.

Uslu and Stausberg, 2008 A.M. Uslu and J. Stausberg, Value of the electronic patient record: an analysis of the literature, Journal of Biomedical Informatics 41 (2008), pp. 675-682

Venkatesh and Davis, 2000 V. Venkatesh and F.D. Davis, A theoretical extension of the technology acceptance model: four longitudinal field studies, Management Science 46 (2) (2000), pp. 186-204.

Yarbrough and Smith, 2007 A.K. Yarbrough and T.B. Smith, Technology acceptance among physicians: a new take on TAM, Medical Care Research and Review 64 (2007), pp. 650-672

Yu et al., 2008 P. Yu, H. Li and M.P. Gagnon, Health IT acceptance factors in long-term care facilities: cross-sectional survey, International Journal of Medical Informatics 78 (4) (2008), pp. 219-229

\section{FIGURES AND TABLES}

Fig. 1. Model to predict the attitude of nursing staff towards using EPR.

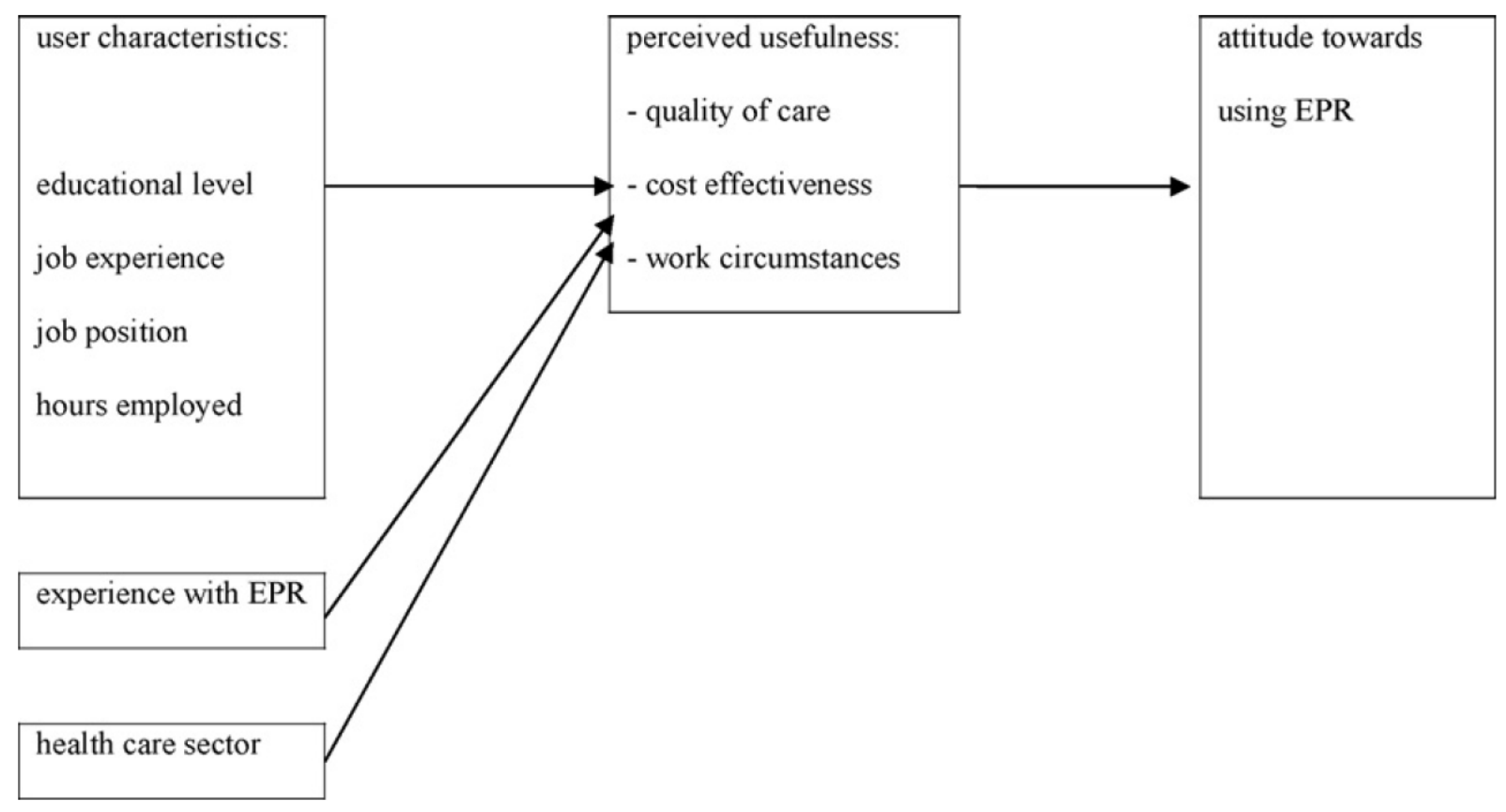

Table 1

Perceived usefulness of EPR $(n=685)$.

\begin{tabular}{|c|c|c|c|c|c|}
\hline Usefulness with respect to & Negative effect & No effect & Positive effect & Mean effect & $95 \%$ confidence interval \\
\hline \multicolumn{6}{|l|}{ Quality of care } \\
\hline Quality of the care given to patient & $9.8 \%$ & $29.9 \%$ & $60.3 \%$ & .67 & $.59 / .74$ \\
\hline Quality of life of the patient & $6.9 \%$ & $63.2 \%$ & $29.9 \%$ & .28 & $.23 / .34$ \\
\hline Independence of the patient & $5.1 \%$ & $75.8 \%$ & $19.1 \%$ & .17 & $.13 / .22$ \\
\hline Safety of the patient & $12.9 \%$ & $31.3 \%$ & $55.8 \%$ & .54 & $.47 / .62$ \\
\hline \multicolumn{6}{|l|}{ Cost effectiveness } \\
\hline Costs of care & $36.3 \%$ & $46.0 \%$ & $17.7 \%$ & -.25 & $-.32 /-.18$ \\
\hline Number of patients that can be cared for & $14.1 \%$ & $64.7 \%$ & $21.2 \%$ & .08 & $.03 / .14$ \\
\hline \multicolumn{6}{|l|}{ Work circumstances } \\
\hline Physical workload & $12.3 \%$ & $77.6 \%$ & $10.1 \%$ & -.04 & $-.09 / .01$ \\
\hline General workload & $43.0 \%$ & $37.2 \%$ & $19.8 \%$ & -.33 & $-.41 /-.26$ \\
\hline Job attractiveness & $23.6 \%$ & $45.3 \%$ & $31.1 \%$ & .09 & $.02 / .17$ \\
\hline Number of administrative tasks & $55.8 \%$ & $13.0 \%$ & $31.2 \%$ & -.46 & $-.56 /-.35$ \\
\hline
\end{tabular}


Veer, A.J.E. de, Francke, A.L. Attitudes of nursing staff towards electronic patient records: a questionnaire survey. International Journal of Nursing Studies: 2010, 47(7), 846-854

Table 2

Perceived usefulness and bivariate relationships with attitudes towards using EPR $(n=610)$.

\begin{tabular}{|c|c|c|c|c|c|}
\hline Perceived usefulness & $n$ & $\%$ & Mean attitude & Test statistic $F$ & $p$ value \\
\hline \multicolumn{6}{|c|}{ Quality of care (13 missing) } \\
\hline No positive effect & 197 & $33.0 \%$ & 1.70 & 140.37 & .000 \\
\hline Positive effect & 400 & $67.0 \%$ & 2.37 & & \\
\hline \multicolumn{6}{|c|}{ Costs of care (18 missing) } \\
\hline No positive effect & 478 & $80.7 \%$ & 2.10 & 8.78 & .003 \\
\hline Positive effect & 114 & $19.3 \%$ & 2.32 & & \\
\hline \multicolumn{6}{|c|}{ Number of patients that can be cared for ( 16 missing) } \\
\hline No positive effect & 463 & $77.9 \%$ & 2.09 & 14.82 & .001 \\
\hline Positive effect & 131 & $22.1 \%$ & 2.36 & & \\
\hline \multicolumn{6}{|c|}{ Work circumstances (13 missing) } \\
\hline No positive effect & 409 & $68.5 \%$ & 2.08 & 10.66 & .001 \\
\hline Positive effect & 188 & $31.5 \%$ & 2.29 & & \\
\hline
\end{tabular}

Table 3

External characteristics and bivariate relationships with attitude towards using EPR $(n=610)$.

\begin{tabular}{|c|c|c|c|c|c|}
\hline External variables & $n$ & $\%$ & Mean attitude & Test statistic $F$ & $p$ value \\
\hline \multicolumn{6}{|l|}{ User characteristics } \\
\hline \multicolumn{6}{|l|}{ Educational level (none missing) } \\
\hline NA & 249 & $40.8 \%$ & 1.97 & 12.37 & .000 \\
\hline RN, associate level degree & 252 & $41.3 \%$ & 2.24 & & \\
\hline RN, bachelor's degree & 109 & $17.9 \%$ & 2.29 & & \\
\hline \multicolumn{6}{|l|}{ Job experience (4 missing) } \\
\hline 9 years and less & 73 & $12.1 \%$ & 2.23 & 0.77 & n.s. \\
\hline $10-19$ years & 206 & $34.0 \%$ & 2.09 & & \\
\hline $20-29$ years & 193 & $31.8 \%$ & 2.12 & & \\
\hline 30 years or more & 134 & $22.1 \%$ & 2.16 & & \\
\hline \multicolumn{6}{|l|}{ Job position (1 missing) } \\
\hline Management & 539 & $88.5 \%$ & 2.12 & 4.60 & .032 \\
\hline Non-management & 70 & $11.5 \%$ & 2.31 & & \\
\hline \multicolumn{6}{|c|}{ Number of hours employed per week (10 missing) } \\
\hline Less than $20 \mathrm{~h}$ (ref) & 135 & $22.5 \%$ & 1.96 & 9.24 & .001 \\
\hline $20-30 \mathrm{~h}$ & 274 & $45.7 \%$ & 2.12 & & \\
\hline $30 \mathrm{~h}$ or more & 191 & $31.8 \%$ & 2.30 & & \\
\hline \multicolumn{6}{|l|}{ Previous experience with EPR ( 3 missing) } \\
\hline No & 314 & $51.7 \%$ & 1.94 & 51.02 & .000 \\
\hline Yes & 293 & $48.3 \%$ & 2.35 & & \\
\hline \multicolumn{6}{|l|}{ Health care sector (none missing) } \\
\hline Hospital & 114 & $18.7 \%$ & 2.54 & 19.13 & .000 \\
\hline Psychiatry & 92 & $15.1 \%$ & 2.29 & & \\
\hline Care for mentally retarded people & 80 & $13.1 \%$ & 2.13 & & \\
\hline Home care & 146 & $23.9 \%$ & 1.82 & & \\
\hline Nursing homes, homes for the elderly & 178 & $29.2 \%$ & 2.08 & & \\
\hline
\end{tabular}


Veer, A.J.E. de, Francke, A.L. Attitudes of nursing staff towards electronic patient records: a questionnaire survey. International Journal of Nursing Studies: 2010, 47(7), 846-854

Table 4

Multiple relationships between external variables and attitudes towards using EPR $(n=574)$.

\begin{tabular}{|c|c|c|c|c|c|}
\hline External variables & $b$ & S.E. & Beta & $t$-Value & $p$ value \\
\hline \multicolumn{6}{|l|}{ User characteristics } \\
\hline \multicolumn{6}{|l|}{ Educational level } \\
\hline \multicolumn{6}{|l|}{ NA } \\
\hline $\mathrm{RN}$, associate level degree & & & & & n.s. \\
\hline $\mathrm{RN}$, bachelor's degree & & & & & n.s. \\
\hline \multicolumn{6}{|l|}{ Job experience } \\
\hline \multicolumn{6}{|l|}{9 years and less (ref) } \\
\hline $10-19$ years & & & & & n.s. \\
\hline $20-29$ years & & & & & n.s. \\
\hline 30 years or more & & & & & n.s. \\
\hline \multicolumn{6}{|l|}{ Job position } \\
\hline \multicolumn{6}{|l|}{ Management (ref) } \\
\hline Non-management & .17 & .09 & .08 & 1.93 & .054 \\
\hline \multicolumn{6}{|l|}{ Number of hours employed per week } \\
\hline \multicolumn{6}{|l|}{ Less than $20 \mathrm{~h}(\mathrm{ref})$} \\
\hline $20-30 \mathrm{~h}$ & & & & & n.s. \\
\hline $30 \mathrm{~h}$ or more & .20 & .08 & .13 & 2.35 & .019 \\
\hline \multicolumn{6}{|l|}{ Previous experiences with EPR } \\
\hline \multicolumn{6}{|l|}{ No (ref) } \\
\hline Yes & .34 & .06 & .23 & 5.40 & .000 \\
\hline \multicolumn{6}{|l|}{ Health care sector } \\
\hline \multicolumn{6}{|l|}{ Hospital (ref) } \\
\hline Psychiatry & -.46 & .10 & -.23 & -4.56 & .000 \\
\hline Care for mentally retarded people & -.38 & .10 & -.18 & -3.68 & .000 \\
\hline Home care & -.56 & .11 & -.32 & -5.21 & .000 \\
\hline Nursing homes, homes for the elderly & -.25 & .14 & -.16 & -1.75 & .081 \\
\hline
\end{tabular}

$R^{2}=.18, F(13,560)=9.67, p=.000$.

Table 5

Summary of four separate regression analyses after adding the perceived usefulness variables $(n=574)$.

\begin{tabular}{|c|c|c|c|c|}
\hline Perceived usefulness as mediating variable & Quality of care & Costs of care & Number of patients & Work circumstances \\
\hline$R^{2}$ & .32 & .20 & .20 & .19 \\
\hline Change in $R^{2}$ & .14 & .02 & .02 & .01 \\
\hline Sign of $R^{2}$ change & .000 & .001 & .001 & .017 \\
\hline Beta & $.38^{* *}$ & $.13^{* *}$ & $.15^{\cdots}$ & $.10^{*}$ \\
\hline External variables after adding mediating variable & Beta & Beta & Beta & Beta \\
\hline \multicolumn{5}{|l|}{ User characteristics } \\
\hline \multicolumn{5}{|l|}{ Educational level } \\
\hline \multicolumn{5}{|l|}{ NA } \\
\hline RN, associate level degree & n.s. & n.s. & n.s. & n.s. \\
\hline RN, bachelor's degree & n.s. & n.s. & $.11^{*}$ & n.s. \\
\hline \multicolumn{5}{|l|}{ Job experience } \\
\hline \multicolumn{5}{|l|}{9 years and less (ref) } \\
\hline $10-19$ years & n.s. & n.s. & n.s. & n.s. \\
\hline 20-29 years & n.s. & n.s. & n.s. & n.s. \\
\hline 30 years or more & n.s. & n.s. & n.s. & n.s. \\
\hline \multicolumn{5}{|l|}{ Job position } \\
\hline \multicolumn{5}{|l|}{ Management (ref) } \\
\hline Non-management & n.s. & $.08^{\circ}$ & $.08^{* *}$ & $.07^{\circ}$ \\
\hline \multicolumn{5}{|l|}{ Number of hours employed per week } \\
\hline \multicolumn{5}{|l|}{ Less than $20 \mathrm{~h}$ (ref) } \\
\hline $20-30 h$ & n.s. & n.s. & n.s. & n.s. \\
\hline $30 \mathrm{~h}$ or more & $.12^{*}$ & $.13^{* *}$ & $.12^{*}$ & $.13^{*}$ \\
\hline \multicolumn{5}{|l|}{ Previous experience with EPR } \\
\hline \multicolumn{5}{|l|}{ No (ref) } \\
\hline Yes & $.23^{\cdots}$ & .24 & .24 & $.25^{\cdots}$ \\
\hline \multicolumn{5}{|l|}{ Health care sector } \\
\hline \multicolumn{5}{|l|}{ Hospital (ref) } \\
\hline Psychiatry & $-.26^{* *}$ & $-.22^{\cdots}$ & $-.21^{* *}$ & $-.21^{\cdots}$ \\
\hline Care for mentally retarded people & -.16 & $-.18^{\ldots *}$ & $-.17^{* *}$ & $-.16^{* *}$ \\
\hline Home care & $-.28^{* *}$ & $-.33^{\ldots}$ & $-.31^{\cdots \cdots}$ & $-.31 \ldots$ \\
\hline Nursing homes, homes for the elderly & $-.16^{* *}$ & $-.16^{*}$ & n.s. & $-.15^{*}$ \\
\hline
\end{tabular}

Betas with a $p$ value $\geq .10$ are omitted.

p value $<.10$

$p$ value $<.05$.

... $p$ value $<.001$ 